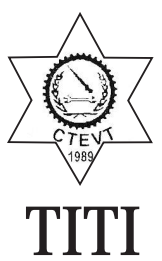

Journal of

Training and Development

2016, Volume 2

ISSN: 2392-456X(Print)

DOI: http://dx.doi.org/10.3126/jtd.v2i0.15439

ISSN: 2392-4578(Online)

\title{
Curriculum Issues In Nepal: A Study On Graduates' Perception
}

\author{
Anup Bhurtel \\ Management Programme \\ Training Institute for Technical Instruction (TITI) \\ Sanothimi, Bhaktapur, Nepal \\ Email for correspondence: abh@titi.org.np or anupbhurtel@gmail.com
}

\begin{abstract}
The study was carried to explore the perception of graduates of mechanical engineering of Technical School Leaving Certificate (TSLC) level perceive about their curriculum after they have entered the job market. The paper is a case study of Balaju School of Science and Technology (BSET) under the Council for Technical Education and Vocational Training (CTEVT) - Nepal in which semistructured interviews of five graduates were conducted. The empirical research has been confined to exploring the perceptions of TSLC: pre-SLC intake graduates of mechanical trade and working inside Nepal. The study has brought forth that the graduates perceive their curriculum positively as the contents were relevant to the job market and the image of their institute was strong; and but they perceive the curriculum negatively since quite a few modules having high demand in the labour market lacked adequate practice, and a few contents were not updated. Besides, poorly managed infrastructure which was not up-to-date and the lack of professional attitude in the instructors impelled them to perceive their curriculum as less effective. On the other hand, the paper also showed the labour market exploiting the graduates despite the curriculum being market focused and graduates being skilful. The paper provides a thorough perspective of such graduates that may serve as a guideline for curriculum developers to address the identified issues. It also opens up the doors for further research to explore the issues in other technical subjects as well as vocational training programmes.
\end{abstract}

Keywords: Technical education, graduates, curriculum and labour market.

\section{Introduction}

The essence of Technical and Vocational Education and Training (TVET) is to produce skilled graduates who are able to enter the world of work with skills and knowledge that the job market demands. TVET is termed as education and training which prepares individual for employment in the job market through acquisition of knowledge, skills and attitude (Ekpo \& Onweh, 2012). It is a means that contributes to human, economic and social aspects of development. UNESCO International Centre for Technical and Vocational Education and Training (UNESCO- 
UNEVOC) has regarded the TVET as a very diverse wing of education and training which enhances skills for employment and further learning (UNESCO UNEVOC, 2013). Technical education and vocational trainings in underdeveloped and emerging economies hold similar significance as general education because of the remarkably low results of general education (Adams, 2007). TVET primarily stresses on fostering employment for which the graduates are required to possess specific job related skills to address the need of the industry. The quality of TVET thus largely depends upon curriculum apart from infrastructure and other resources. Schnarr, Yang and Gleibner (2008) have related the strength of TVET system with its ability to offer and design wide variety of courses as per the demand of labour market.

In Nepal, the Council for Technical Education and Vocational Training (CTEVT) operates as the biggest umbrella organization in the TVET sector and holds the prime responsibility of producing skilled labour workforce through TVET programmes and has its own act to formulate and revise policies on TVET. As the state-owned apex body, it produces the majority of TVET graduates for the nation. The CTEVT offers programmes both in technical education and short- term vocational training to address the market needs of Nepal. It enrols the students in Diploma or Proficiency Certificate Level (PCL) programmes and Technical School Leaving Certificate (TSLC) programmes that include both its constituent and affiliated schools (Council for Technical Education and Vocational Training [CTEVT], 2014). Under technical education, the diploma/PCL curricula are being used in the subjects such as agriculture - (plant and animal science), engineering, heath/nursing, forestry, tourism, humanities; and there are several other curricula in technical subjects. Among the courses offered in engineering is Diploma in Mechanical Engineering and TSLC level in Mechanical Engineering as well. Even in this, the programmes have been categorized to TSLC in mechanical engineering-Pre SLC level which was revised in 2014 and TSLC in mechanical engineering-Post SLC level which was formulated in 2005 and not yet revised (CTEVT, 2014).

The graduates are produced to unlock the gate of job market though the acquisition of necessary skills and knowledge the industry demands. However, the demands of industry change with the change in needs of the market. It is the effectiveness or ineffectiveness of curriculum that may provide the graduates the opportunities; or compel them to face challenges in finding jobs or sustaining in the job. The true effectiveness of the curriculum can therefore be depicted by those graduates who actually have faced the circumstances in the real world of work. In this context, this paper has made an attempt to understand how the graduates of TSLC: Pre-SLC Intake in mechanical engineering from Balaju School of Science and Technology (BSET) under CTEVT (further known as graduates in this paper), who are actually working in the labour market, perceive about their curriculum with respect to the labour market in Nepal. The empirical research also tries to unearth the issues they have faced after stepping out for employment and starting to work, and to explore their perceptions.

\section{Curriculum Issues in Nepal}

One of the significances of competence of individual is reflected in driving socio-economic changes (Merki, 2008). Buchman and Huisinga (2008) have presented the concept of competency as the capability and as the sphere of responsibility or the field of authority. Skills are the essential factors to build up competency. The industry demands graduates who gain proficiency in skills and display competency in quality work. It is the curriculum based on which competency is gained in TVET. Sharma (2010) adds that the success of TVET curriculum is measured by the achievement results of the performance that the graduates demonstrate in the real world rather than their educational achievement. However, the needs of industries constantly change with the change in the technology and the market needs. They not only demand for skilled workforce, but also for updated technical knowhow in them. The changes in curriculum with the changes in industry needs 
thus can be the strategy to retain its quality for the CTEVT. Netherlands Initiative for Capacity development in Higher Education (2010) has put forward the out-dated curricula and its lack of relevancy with the revolutionizing trends in industries as the issue with the quality of TVET in developing nations. As Dahal (2010) reveals curriculum as the third most important factor out of 23 relevant ones for quality trainings, the efficiency of TEVT thus depends upon its ability to supply skilled graduates to the labour market by exploring their needs which is also the case in Nepalese job market.

The issue regarding the delay in timely updating or no updating of the TEVT curricula in line with the changing needs of job market still prevails in Nepal. Shrestha (2011) reveals that some of curricula have been unchanged for years and instructors are not given 'Refresher Trainings to update them with the changed curricula. A few programmes of the CTEVT's vocational trainings date back to as early as 1995. In PCL/Diploma courses, quite a few courses offered have not been revised for a decade (CTEVT, 2014). Lamichanne (2013) adds up that some curricula and teaching equipment are as old as 15 and 30 years respectively. Jha (2014) has identified that in the programmes at Proficiency Certificate Level, some contents and topics are of less use in the current context and need to be removed; and hours and contents of some of the subjects need to be expanded and revised. The author has stressed on the need of restructuring the curriculum to attract not only the students, but also the employers. In the Nepalese context, the industry needs are not found to be thoroughly studied while developing a curriculum; and the training for faculty members in emerging fields as stipulated in the curricula are not provided. Thus, the quality of the TVET declines and the graduates suffer due to the discrepancy between demand and supply of skills. Researchers have identified pertinent reasons for 'relevancy issues' of curriculum in the Nepalese context. Badal (2010) has specified that the absence of a solitary system to make a standardized format applicable for the whole nation is one of the existing issues in
Nepal and reasons having a difficulty in satisfying labour market needs. He adds that private or public organizations are functioning with their own curricula and not all of them may have been revised. Due to this, inconsistency prevails in curricula on the same trade. Jha (2013) and Khanal (2013) present the cause of the inconsistency and incapability to respond to industry needs as the absence of functioning labour market information system. Besides, the failure in timely revision of the courses and content inclusion has also been addressed by the TVET researchers. Sharma (2010) addresses the absence of soft skills in TVET curricula as another issue.

Amidst the density of adverse deterrent curriculum issues, some researchers review TVET curricula positively. Basnet and Basnet (2014) advocate that the objectives and course/programme contents of the curricula in TVET are rooted from the consideration of occupational standards and investigation of the jobs/tasks done in the workplace. Lamichhane (2013) highlighting the transfer of TVET plan to implement demand-driven curricula from supply-driven ones in Nepal, assures the capability of present TVET curricula to address the need of domestic market. The author discloses one of the achievements and model practices as the uniform and synchronized curricula development system that uses DACUM (Develop a Curriculum) process in Competency Based Model applied in the nation. One strength of public-private partnership lies in curriculum development based on which practical classes are taken and On-The-Job (OJT) trainings are provided. Kafle (2014) also explains that Technical Education Curriculum Assessment (TECA) of CTEVT has aimed at enhancing competencies in the industry, technical precisions, and profound knowledge on pedagogy to produce competent technicians. TVET curriculum provides equal information on the subjects taught or trained and produces graduates of comprehensive nature with overall knowledge of the curriculum (Jha, 2014). Though this indicates the need for specialization, this also allows them to pursue higher level of courses with specialization of their choice after having overall 
understanding of the scopes of each programme. As presented by Ghimire (2013), one of the strengths of the CTEVT is its expertise in developing competency-based curriculum and conducting assessment based on the student performance as well. Hence, literature and documents show that the TVET curricula in the Nepalese contexts have addressed the market situation.

It is the perception of those graduates, who are facing the challenges to get opportunities to enter the industry or are working there, that helps analyse whether curriculum were market oriented or not. Hence, understanding the crux of issues related to the TVET curriculum by exploring the graduates' perceptions has been felt necessary. The study has thus made an attempt to explore how the graduates perceive about their curriculum. It also aims to explore the other pertinent issues that the graduates have faced in the industry related to the TVET curriculum.

\section{Research methodology}

I conducted this research under interpretive paradigm. The paper follows qualitative approach in which rich source of information has been gathered from a few participants. Qualitative approach is concerned with gathering qualitative data such as perceptions, beliefs and understandings of a few people and mapping the meanings, processes and contexts (Ritchie, 2003). Adopting the case study method of interpretive paradigm, I purposefully selected and interviewed five graduates from BSET. In case study, the researchers explore an activity or process of single individuals, communities or organizations in depth, to understand the phenomenon (Creswell, 2003; Ticehurst \& Veal, 2000). As explained by Ritchie (2003), case study can be summarized as the study of an array of perspectives rooted in an explicit context and this goes in line with the research objective of this paper.

Qualitative methods allow the researcher to collect data in relatively less formal environment. On top, interviewing as a common technique of conducting qualitative research allows the participants to respond in a more elaborative way (Creswell, 2003). Thus, this allowed me to gather data in detail, analyze the finding from multiple perspectives to justify the research methodology itself. It has also allowed me to respond immediately to what answers participants share by tailoring subsequent questions to information the participant has provided. Among the available interviewing technique, semi-structured interview offers flexibility to modify interview guidelines as per responses and situation to collect rich and explanatory answers (Chrzanowska, 2003). Thus, using semi-structured interview, I garnered initial responses from the participants by using probing technique. The probing technique also helped the participants to respond in their own words, provide broad range of responses rather than obligation to select one from a fixed range of responses.

Interviews should be conducted by building a working relationship with the participants and making them comfortable (Ritchie, 2003; Chrzanowska, 2003). Hence, I started the interviews by building a good rapport and assuring them of data confidentiality. I commenced both the interviews by informing them that the identity of the interviewee would be kept anonymous. I have used pseudonyms in my paper accordingly. In required instances, I reassured them about the research ethics, after which the participants provided unanticipated answers, which were quite fruitful to my paper.

I analyzed the data obtained from interviews through the 'framework method' of thematic analysis as stated by Ritchie \& Lewis (2003); and brought forward the discussion by substantiating with relevant researches and theories. I implemented purposive sampling as the research nature required participants to be based on preselected criteria. In this regard, I purposefully selected five graduates who were actually working in the Nepalese job market in the mechanical sector only rather than those who were searching for job or applying for foreign employment. As suggested by Ritchie \& Lewis, I took the sample size of five participants considering the time resource, 
theoretical saturation implying the phase where new responses from them no longer would bring new insights to the research question.

\section{Analysis and discussion}

\section{Graduates' experiences in the labour market}

I initially made an attempt to explore the ease or difficulty the participants experienced to find the job or to sustain in the labour market as the fresh graduates. To this query, a few responded that they used personal connection either through personal link or during the On-the-Job training (OJT). They openly shared that if it was not for their prior linkage with the employers, they would have remained unemployed till date. To this standpoint, Ajay (pseudonym) shared: "In my case, it was not difficult to find this job as I had connection. However, I had hardship while looking for jobs at other places. How can a fresh graduate show years of experience to be saleable?" It clearly states that the personal linkage with the industry was as important as being skilful. It depicts the practice of 'vertical dyad linkage'. The theory of vertical dyad linkage maintains that among the two groups viz. 'in-group' and 'out-group' formed through a dyadic relationship between the leader and the subordinates, the in-group members have access to more resources, have a say in decision making process and receive privileges at work (Dansereau, Graen \& Haga, 1975). It shows that this theory persists in the Nepalese labour market; and this is revealed through the experiences of these graduates with the vertical dyad linkage (in-group membership).

The participants disclosed during the interview that the image of the institute (BSET) was good in the labour market and this also helped them find the job. The image of the CTVET and precisely the BSET was found to have been taken positively and had a positive image. As stated by Puusa and Tolvanen (2006), organizational identity usually is portrayed as that which is core, distinctive, and enduring about the character of an organization; the identity of an organization helps spread an image in the industry; and the image builds trust in the industry. Thus, it shows that the strong identity of the institute may help the graduates be saleable in the market.

\section{Graduates' perception on 'what the labour markets demand'}

While exploring demands of the employers based on the participants' individual experiences, most of them revealed that the job experience was the key factor. They all shared a common story of the inevitable struggles they all went through being fresh graduates. Besides, they shared that the demands of employers were based on what they produce for the consumer market; and they demand overall competencies to perform in the workstation. The employers seek proficiency in the graduates. They not only seek psycho-motor skills, but also soft skills, overall attitude and having a preferred team player spirit rather than just a skill performer. Albeit they seek such qualities, they commonly exhibit an exploitative attitude and demand more inputs/contributions with less pay. In his voice/tone filled with sorrow, Chandra (Pseudonym) disclosed:

"...Truth be told, the work is hard and there is no specific time table. The work starts from seven or eight in the morning till five in the evening but they do not provide breakfast or lunch. Here, the salary isn't good to tell you frankly. That makes it difficult to work as they are reluctant to offer facilities but push us to do hard labour."

It clearly indicates that the graduates experienced direct or indirect exploitation by the employers as it was inherent for them to demand more labour on less pay and facilities. It indicates that the exploitative attribute amongst employers is common in the nation. The Marxian theory of exploitation of profit as described by Mohun (2003) asserts that employers, mostly private, allow the handful of privileged to reap the benefits of the labours of others without needing to contribute. The capitalists use labour power to create more value by compensating the labourer well to reproduce the commodity. This in turn, produces added and surplus value for the owner. However, the workers are exploited upon failing to keep or control the value created by their own labour 
power (Kliman, 2001). The perspective of the participants shows that this theory is pertinent as the practice is found to be widely in existence. Hence, they are suffering in the job market.

While digging up and discussing about the experiences, another striking fact came into light which falls under 'work culture' dimensions. As one participant, feeling comfortable, shared:

"To tell you bhitri kural, what I saw was that the employers and seniors at work often seek respect and are cautious about prestige. More than work proficiency, they wanted to show power distance, wanted to be treated with superiority. Yes, they also look up for skills, but far more than this, what I observed was they want to show that they are seniors to ensure their dominance." (Dil: Pseudonym)

Based on this disclosure, I inferred that power distance prevails in Nepalese labour market. Hofstede's construct of power distance was explained by Brockner et al. (2001) as the extent to which inequality in existence and practice among individuals working in different positions of formal power is viewed as a natural and even preferable facet of the social order. The proposal of Hofstede that was broadly based cultural values spill into the world of work also was confirmed later (Bochner \& Hesketh (1994). Thus, keeping the superiority complex of employers in consideration, the construct of power distance is found to be high in the Nepalese labour market.

\section{Perception on the curriculum with respect to the labour market}

Following the above experiences and perceptions, I proceeded towards exploring on how they perceived about curriculum with respect to the labour market and that gave me a notion of multiple realities through a wide range of responses. A few found their curriculum practical and their work in the industry was similar. The respondents were found to be using the skills and knowledge they acquired during their course and were doing more or less similar jobs. They perceived the curriculum stronger due to the renowned image of their institute. They found contents/practice in workshops quite relevant, and were able to demonstrate their skills effectively in their world of work. The participants mainly perceived their curriculum as useful and relevant considering the modules they studied. The contents such as welding, fabrication, tasks on lathe machines were expressed their as strengths considering the demands and relevance in the job market. Showing their consent on relevance of curriculum to cater to the needs of general mechanical sector in the industry, Kumar (Pseudonym) further shared:

"In my opinion, having contents like Milling, fabrication and welding: Tungsten Insert Gas (TIG) welding and Metal Insert Gas (MIG) welding which are rare in the market is strong point of our curriculum..."

This shows that curriculum has been developed and revised keeping consideration the nature of works carried out in the mechanical sectors in different industries of Nepal. Having On-The-Job training (OJT) in the curriculum was also taken as strength of the curriculum. In addition, I found that they also perceived their curriculum as effective also due to the competent instructional skills of the instructors. Hence, it shows that the teachers' ability to demonstrate the skills clearly and carefully and deliver the sessions competently was taken positively by them.

Furthermore, in contrast to such positive perspectives, the participants also expressed that their curriculum was less effective because of it not having a few essential contents such as repairing, maintenance and bearing. Besides, some important modules, though highly in demand, were taught for short time and it was not sufficient to perform those skills competently and confidently. It vividly shows the incomprehensiveness of the content and inadequacy

1 bhitri kura is a Nepali term that refers to inside story or the fact that is not usually disclosed/exposed to others outside 
of the practice time as the key curriculum issues; and I have therefore interpreted in this paper that the identified curriculum issues are inclusive of the inability to update with the changing demand of industries. The findings of Sabharwal (2013) also align with my inferential standpoint that in the employment ecosystem of TVET (comprises of assessment, curriculum, certification and jobs) and the poor alignment between skills training and employment ecosystem still prevails. The author adds that the employability mismatch tends to continue until the training providers seriously commit to understand market demands and trends for skills including soft skills such as employability skills and include these in their curriculum and certify with certain skill sets.

An interesting sphere of curriculum, that makes a difference to its effectiveness that I explored, was the part of the management that plays a role in running a course. The participants shared with me that the poor management of the institute has made an unpleasant impression in their minds. In a saddening tone, Chandra shared: "So far I can remember, there being five or six lathe machines in BSET's workshop but the one that did work properly were barely one or two." Bikram (Pseudonym) also opined with similar tone with regard to the workshop management. He added:

"In our curriculum, I perceived a few modules such as TIG and MIG welding as its strength and I have heard that this content is not available in other places. But honestly speaking, it is not good as it used to be. Sometimes they say they do not have certain required tools/materials and the whole session gets halted. If some parts break down in the workshop, they take ages to make it work. How much could we learn in such circumstances? Considering this, there is no valid point of including this module in the curriculum. Isn't it?"

It reveals that the poor management of the infrastructure poses an undeniable threat to the effectiveness of curriculum. A curriculum cannot be effective if the management is not effective. As traced by Lamichanne (2013), decades old equipment has deterred the quality of curricula and TVET. I therefore came to the standpoint that not only contents, but also active and functioning administrative unit should be there for smooth and regular classes' management; and this should be ensured by the school management committee.

\section{Graduates' perspective on an ideal curriculum}

Upon digging on the perceptions of the graduates about what would be an ideal curriculum, I explored their perspectives based on their own individual experiences. They stressed that the time to teach entrepreneurship skills development should be extended to at least a month to promote the graduate with capital and/or interest in investment to be selfemployed. They opined that including team building skills, communicating skills at work would be fruitful and expanding these modules up to even one whole year would not be a bad idea. It can be thus inferred that the curriculum would only be ideal if soft skills along with the hard skills, were included and taught in depth so that they could apply those skills in their job. The graduates are found to be facing the problem related to gap between supply and industry need, one of which is related to the soft skills. Sharma (2010) states that there is a lack of contents that teach various soft skills such as communication skills; decision making; problem solving skills and such in the TVET curricula. The curricula are also not found to have adequate contents and time duration on entrepreneurship skills. Thus, consistent with my interpretive standpoint, Sabharwal (2013) also stresses on entrepreneurship skills to address unemployment issues. Market-based curricula with the inclusion of soft skills have also been outlined to solve the problem of unemployment (Netherlands Initiative for Capacity development in Higher Education, 2010).

They expressed their opinion that the curriculum of the exiting duration would be relevant if practical classes of the modules more in demand in the industry 
were adequately included.. Besides that, the common opinions expressed by the respondents were changes in the modules or contents focusing on in-depth teaching of skills demanded by the labour market; and making sessions practice-oriented with abundant guided and independent practice. This discloses that in order for such curriculum in technical education to be strong, it should address changing demands of job market, and should be revised based on market and technological changes. To enhance TVET quality, Jagannathan (2012) has brought forward several issues to consider, one of which is adaptable approach to curriculum maintenance keeping in line with the rapidly changing technology in the market. Valles (2012) on the other hand, stresses that programme curricula should be designed in collaboration with the professional community and those responsible for technical and vocational education. A paper on NICHE strategy on Technical and Vocational Education and Training (TVET) stresses on the significance of industry-driven curricula with technological updates and market focus to solve the problem of unemployment (Netherlands Initiative for Capacity development in Higher Education, 2010). As opposed to underdeveloped nations such as Nepal and Bangladesh, in emerging economies like Malaysia and Thailand, TVET policy makers have prioritized the improvement plan of TVET by carrying out certain plan of actions, one of which is aligning TVET curriculum with the demand of labour market (Martinez-Fernandez \& Choi, 2013). Thus, as suggested by Chenoy (2013), to strengthen TVET, the system should shift its base to competency based training and develop or revise demand-driven curricula that address the needs of labour market. With regard to curriculum development, Wang, Khan and Zhang (2013) have disclosed that the curriculum developers having the centralized control mechanism and being backed up by the state lack in identifying the circumstances of the rural areas or places away from the urban. In Nepal's TVET scenario, it is the CTEVT as a state owned council that holds the responsibility of developing and revising curricula of technical education and vocational training by forming a curriculum development committee.
Hence, it can be interpreted that the gap between the supply and demand of labour market can be substantially reduced by heavily involving the graduates of respective courses as well in the curriculum development committee.

The respondents also revealed that strength in curriculum could be ascertained in the market if the machines in the workshop were in working conditions, and similar to those in the market. Pinpointing the decades old and partly functioning Swiss lathe machines in the workshop of BSET, they disclosed that more than change in curriculum, the machines in the workshop should be changed keeping the industry needs in mind. They also impelled on addition of automatic or Computerised Numerical Control (CNC) machines for the graduates who have to handle such machines in some industries in Nepal and in foreign employment. Ajay thus summed up his opinion as: "...I think even if the curriculum is strong itself, for me, this curriculum would be ideal if the course providers offer up-to-date machines used in the market." Here, I inferred that curriculum would be ideal if it is market based; and if the infrastructures for teaching respective curriculum are also market-oriented and up to date. As stated by Maclean, Jagannathan, and Sarvi (2013), the investment done in TVET is often paralleled with certain critics. It is because the development of curriculum entails heavy expenses as it requires expertise and resources; and provides the guideline for necessary infrastructure such as training materials and equipment, classroom facilities and such. Even though the curriculum of TSLC in Mechanical engineering: pre-SLC intake was revised in 2014, the issues raised at that time were that the demands were not seriously addressed and the market study was inadequate before the revision.

In reference to the existing labour market, the participants opined that the job placement unit should spend more time and effort to identify potential job markets that do keep the welfare of the graduates in shadow. The unit should intensely lobby with them and maintain healthy relationships. They added that 
the curriculum should include substantial number of orientation sessions about the real world of work to mentally prepare them as they would be facing uncertain and unprecedented circumstances in the labour market. This illuminates that the active involvement of the job placement unit as well as the entire school management realizing their key mandatory roles are considered as an impetus to fortify the perspectives of curriculum.

One of the key points I explored was that the commitment and overall attitude of the instructors also are necessary to improve the curriculum standard. One participant shared:

“... What happens is they do not tend to teach or share the knowledge and skills they possess. Curriculum in itself is not that bad. No matter how relevant and useful contents you include, no matter how advanced contents you include, if the instructors who teach this curriculum do not do their job sincerely, it would make no sense. (Pauses feeling little awkward; and continues upon reassurance of researcher's ethical consideration). We had frequently seen that some instructors go to the canteen to have a cup of tea assigning us practical work in workshop. This is so wrong. (In a depressing tone)I am telling you honestly sir. To bring forward the curriculum as competent, these things must be addressed first." (Kumar)

This striking fact helped me come to a standpoint that the instructors have a major stake in how the graduates perceive about their curriculum. It clearly reveals that a curriculum cannot be deduced as effective just because it is market-oriented and is equipped with infrastructure. The instructors must be professional with strongly positive attitude. Here I also analyzed that more than the management unit, it is the instructor/teacher who holds key responsibility to ensure ahead that the workshop has everything arranged to conduct the classes without halt, and pressurize the management upon delay in addressing the issues. Albeit the instructors have knowledge and skills, it cannot assure effective and smooth classes if the attitude is poor. In line with this, Kerre (2009) adds that while developing and revising market oriented curricula, the issues regarding development of the knowledge, skills and attitude in the instructors or teachers are often ignored. The author hence illuminates the role of the instructors as a determinant of the quality of the curriculum; and thereby stresses on the necessity of development of positive attitude along with knowledge and skills in them. Maclean \& Lai (2011) also infer that polishing the competence of teachers up to the proficiency level transforming from imparting knowledge to facilitating learning will ultimately enhance the image of the curricula.

\section{Practical and research and implications:}

The discussion manifests interesting avenues for practical implications for curricula developers so as to address industry needs and the other identified issues. As the paper was limited to exploring the perceptions of graduates of the TSLC mechanical engineering stream, further research of the graduates from other streams and levels; as well as of the employers can be done to depict the true pictures/scenarios of the labour market and also to explore wide range of perceptions on how the TVET curricula stand in the labour market.

\section{Conclusion:}

This research has delineated the perceptions of graduates working in the job market on their curriculum with respect to the labour market where they are currently employed. Curriculum stands as one of the explicit determinants of TVET's effectiveness and the existing curriculum is perceived positively as it provides the knowledge and skills the employers basically look for. But the graduates find it hard due to lack of personal references and employers' innate tendency of exploiting the labours which is a little beyond the scope of the curriculum effectiveness. They perceive their curriculum less effective in the context that a few in-demand contents need to be updated or revised with more practical classes and also addressing pertinent technological 
changes in both national and international job market. Moreover, the perception of the curriculum in a comprehensive sphere has been affected by the instructors' lack of competiveness and professional attitude. Strong TVET increases productivity and helps in creating employment opportunities; and to achieve this, it is imperative that the curricula developers address the issues of changing market needs, technology as well as produce competent human resources with sincere attitude. Only after this, the effectiveness of strong curricula can be justified and the TVET can produce competent graduates needed by the industries to lead nation towards development and prosperity.

\section{Acknowledgements}

I am grateful to Mr. Amit Koirala, Research Department, Training Institute for Technical Instruction (TITI), for his scholarly guidance and Mr. Mohan Prasad Bhurtel, Training and Curriculum specialist, World Education Inc., Kathmandu, Nepal for his technical assistance while shaping up this research work. A sincere gratitude goes to Mr. Pushpa Raj Paudel, Curriculum Division, TITI, for his valuable insight in the subject matter. I am also indebted to Ms. Monika Sapkota, Scholar at University of Edinburgh, United Kingdom for her continuous scholarly support in writing this research paper.

\section{References}

Adams, A. V. (2007). The Role of Youth Skills Development in the Transition to Work: A Global Review. Washington, D.C: The World Bank. Retrieved from http://siteresources.worldbank.o rg/INTCY/Resources/395766-118789951 5414/RoleofYouthSkills.pdf

Badal, B. (2010).Principles and Practices of Curriculum Development in TVET. Technical and Vocational Education and Training Development Journal, 1(10), 131-139. Retrieved from http://www.ctevt.org.np/files/Re search\%20Journal\%202010.pdf
Basnet, K. B., \& Basnet, H. B. (2014). Regulation of Technical Education and Vocational Training (TEVT) in Nepal. Technical and Vocational Education and Training Development Journal. 1(10), 26-33. Retrieved from http://ctevt.org. np/files/Research\%20Journal\%202014.pdf

Bochner, S., \& Hesketh, B. (1994). Power Distance, Individualism/Collectivism, and Job-Related Attitudes in a Culturally Diverse Work Group. Journal of Cross-Cultural Psychology 25(1). 233-257. doi: 10.1177/0022022194252005

Brockner, J., Ackerman, G., Greenberg, J., Gelfand, M.J., Francesco, A. M., Chen, Z. X., Leung, K., Bierbrauer, G., Gomez, C., Kirkman, B. L., \& Shapiro, D. (2001). Culture and Procedural Justice: The Influence of Power Distance on Reactions to Voice. Journal of Experimental Social Psychology, 37, 300-315.doi:10.1006 /jesp.2000.1451

Buchmann, U., \& Huisinga, R. (2008). Curriculum Research and Development. Handbook of Technical and Vocational Education and Training Research. Bremen: UNEVOC, 511-516

Chenoy, D. (2013). Public-Private Partnership to Meet the Skills Challenges in India. In Skills Development for Inclusive and Sustainable Growth in Developing Asia-Pacific (pp. 181 194). doi: 10.1007/978-94-007-5937-4_10. Dordrecht: Springer

Chrzanowska, J. (2003). Interviewing groups and individuals in qualitative market research. London: Sage.

Council for Technical Education and Vocational Training. (2014). A profile of technical and vocational education providers 2014. Bhaktapur: Author.

Cresswell, J. W. (2003). Research design: Qualitative, quantitative, and mixed methods approaches 
(2nd ed.). Thousand Oaks: Sage.

Dahal, D.P. (2010).A model of TVET quality framework for Nepal. Technical and Vocational Education and Training Development Journal, 1(10), 98-108. Retrieved fromhttp://www.ctevt. org.np /files/Research\%20Journal\%202010.pdf

Dansereau, F., Graen, G., \& Haga, W. J. (1975). A vertical dyad linkage approach to leadership within formal organizations: A longitudinal investigation of the role making process. Organizational behavior and human performance, 13(1), 46-78.doi: 10.1016/0030 5073(75)90005-7

Ekpo, A. B. \& Onweh, V. E. (2012). Coping with the global economic crisis: A challenge to technical vocational education and training (TVET) in Nigeria. An International Multidisciplinary Journal, 6(3), 165 - 175. doi: 10.4314/afrrev.v6i3.12

Ghimire, S.S. (2013). Developing the strategies to strengthen Council for Technical Education and Vocational Training, in Nepal. Technical and Vocational Education and Training Development Journal, 1(13), 105-113. Retrieved from http://ctevt.org.np/files/Research\%20Journal\% 202013.pdf

Jagannathan, S. (2012). Lessons for skills policy frameworks. OECD Local Economic and Employment Development (LEED) Working Papers, (12), 43-48.

Jha, W. (2013). Gap between theory and practice of curriculum in TVET of Nepal. Technical and Vocational Education and Training Development Journal, 1(13), 123-129. Retrieved from http://ctevt.org.np/files/Research\%20Journal\% 202013.pdf

Jha, W. (2014). Need for re-structuring PCL TVET curriculum of Nepal. Technical and Vocational
Education and Training Development Journal, 1(14), 76-84. Retrieved from http://ctevt.org.np /files/Research\%20Journal\%202014.pdf

Kafle, A.P. (2014). Individualized learning. Technical and Vocational Education and Training Development Journal, 1(14), 41-47. Retrieved from http://ctevt.org.np/files/Research \%20Journal\%202014.pdf

Kerre, B. W. (2009). A Technical and Vocational Teacher-Training Curriculum. In International Handbook of Education for the Changing World of Work (pp. 1319-1332). doi:10.1007/978-1 4020-5281-1_88. Springer: The Netherlands

Khanal, G. (2013). TVET policy, 2012: Ambitious or achievable? Technical and Vocational Education and Training Development Journal, 1(14), 5-8. Retrieved from http://ctevt.org.np/files /Research\%20Journal\%202013.pdf

Kliman, A. J. (2001). Simultaneous valuation vs. the exploitation theory of profit. Capital \& Class, 25(1), 97-112. doi: 10.1177/03098168010 7300106.

Lamichhane, R.H. (2013). Strategic directions for CTEVT for skilling Nepal. Technical and Vocational Education and Training Development Journal, 1(13), 14-22. Retrieved from http://ctevt.org.np/files/Research\%20Journal $\%$ 202013.pdf

Maclean, R., \& Lai, A. (2011). Editorial: The future of technical and vocational education and training: Global challenges and possibilities. International Journal of Training Research, 9(1-2), 2-15. doi: 10.5172/ijtr.9.1-2.2

Maclean, R., Jagannathan, S., \& Sarvi, J. (2013). Skills Development Issues, Challenges, and Strategies in Asia and the Pacific. In Skills Development for Inclusive and Sustainable Growth in Developing Asia-Pacific (pp. 3-28). 
doi: 10.1007/978-94-007-5937-4_1. Dordrecht: Springer

Martinez-Fernandez, C., \& Choi, K. (2013). Skills Development Pathways in Asia. In Skills Development for Inclusive and Sustainable Growth in Developing Asia-Pacific (pp. 155 180). doi: 10.1007/978-94-007-5937-4_9. Dordrecht: Springer

Merki, K. M. (2008). Cross-curricular competencies. In Handbook of Technical and Vocational Education and Training Research (pp. 517-523). New York, NY: Springer.

Mohun, S. (2003). On the TSSI and the Exploitation Theory of Profit. Capital \& Class, 27(3), 85 102. doi: 10.1177/030981680308100107.

Netherlands Initiative for Capacity development in Higher Education. (2010). NICHE strategy on Technical and Vocational Education and Training (TVET). The Netherlands organization for international cooperation. Retrieved from https://www.nuffic.nl/en/library/niche-strategy on-technical-and-vocational-education-and training-tvet.pdf

Puusa, A., \& Tolvanen, U. (2006). Organizational identity and trust. Electronic Journal of Business Ethics and Organization Studies, 11(2), 29-33. Retrieved from https://jyx.jyu.fi/dspace /handle/123456789/25384

Ritchie, J., \& Lewis, J. (2003).Qualitative research practice: A guide for social science students and researchers. London: Sage.

Sabharwal, M. (2013). Education, Employability, Employment, and Entrepreneurship: Meeting the Challenge of the 4Es. In Skills Development for Inclusive and Sustainable Growth in Developing Asia-Pacific (pp. 67-88). doi: 10.1007/978-94 007-5937-4_4. Dordrecht: Springer
Schnarr, A., Yang, S., \& Gleibner, K. (2008). Vocational education and training in the labour market - a comparative analysis of China and Germany. Germany: UNEVOC. Retrieved from http://www.unevoc.unesco.org/fileadmin/ user_upload/pubs/VETandLabourMarket.pdf

Sharma, T.N. (2010). Technical vocational education and training focusing on soft skills in reference to school sector reform in Nepal. Technical and Vocational Education and Training Development Journal, 1(10), 5-17. Retrieved from http://www.ctevt.org.np/files/Research\% 20Journal\%202010.pdf

Shrestha, D.K. (2011). Curriculum revision for effective TVET. Technical and Vocational Education and Training Development Journal, 1(11), 92-96. Retrieved from http://ctevt.org.np /files/Research\%20Journal\%202011.pdf

Ticehurst, G. W. \& Veal, A. J. (2000).Business research methods: A managerial approach. Frenchs Forest, NSW: Longman.

UNESCO UNEVOC (2013).Conceptual and position paper: Technical and vocational education and training. Santiago: Author

Valles, M. C. (2012). Integrated skills: an approach for strengthening the Technical and Vocational Education Program (STVEP) in the Philippines. OECD Local Economic and Employment Development (LEED) Working Papers, (12), 71 76.

Wang, L., Khan, Q. U., \& Zhang, D. (2013). In Skills Development for Inclusive and Sustainable Growth in Developing Asia-Pacific (pp. 89-104). doi: 10.1007/978-94-007-5937-4_12. Dordrecht: Springer 